\title{
MUDÉJARES VALENCIANOS VIAJAN A GRANADA
}

\author{
Por \\ LUIS F. BERNABÉ PONS
}

El mantenimiento de la lengua árabe entre la población musulmana de Valencia posterior a la conquista del siglo XIII resulta un hecho a estas alturas incontrovertible, por más que se haya visto precedido en su estudio de afirmaciones sin demasiada base científica y que haya sido hasta muy recientemente puesta en duda ${ }^{1}$.

El Reino de Valencia se significa, junto con Granada, como la única zona geográfica hispana donde el uso del árabe se mantendrá hasta el mismo momento de la expulsión de los moriscos en 1609 , y la problemática de ese uso con respecto a las autoridades religiosas cristianas, especialmente en el siglo XVI, puede ser rastreado en los abundantísimos testimonios inquisitoriales o en las propias declaraciones de los religiosos encargados de la evangelización de la población musulmana ${ }^{2}$.

(1) Vid. el resumen de la discusión, a partir de la opinión que él denomina "tradicionalista", en R. I. Burns, "La muralla de la llengua. El problema del bilingüisme i de la interacció entre musulmans i cristians al regne medieval de València", L'Espill, 1/2 (1979), pp. 15-24. Vid. también M. C. Barceló, "La llengua àrab al País Valencià (segles VIII al XVI)", Arguments, 4 (1979), pp. 123-149 y D. Bramon, "Una llengua, dues llengües, tres llengües", en: Pere Sisé, Raons d'Identitat del País Valencià, València, 1977 , pp. 17-47.

(2) Para Burns, la opinión tradicional se ve alterada sustancialmente a partir del libro de Joan Fuster Poetes, moriscos $i$ capellans (València, 1962), quien, tras utilizar los abundantes documentos referidos a los moriscos recogidos por P. Boronat y Barrachina (Los moriscos españoles y su expulsión, Valencia, 1901), concluye que la cultura "gairebé exclusivament aràbiga entre els moriscos valencians del segle XVI implica l'existència d'un règim plenament àrab abans de la croada 
Es conocido que los privilegios que fueron concedidos a los musulmanes después de la conquista reconocían a éstos el derecho de seguir usando la lengua árabe y de enseñársela a sus hijos. De esta manera, la comunidad mudéjar continuará usando su lengua materna amparada por la autoridad oficial ${ }^{3}$, la cual, a su vez, comenzará a procurarse el servicio de traductores de árabe para la cancillería real.

Durante los siglos XIV y XV el árabe, pues, será la lengua "oficial" de la comunidad mudéjar valenciana en tanto que reconocida por la autoridad real. Aunque todavía no estamos muy bien informados acerca de los modos de comunicación entre la comunidad islámica y la cristiana, sí observamos que el árabe funciona en pie de igualdad con la lengua romance en cuanto lengua de comunicación oficial. De la misma forma, su uso interno dentro de la comunidad islámica había de ser uniforme, si bien no puede precisarse con exactitud en qué medida este conocimiento del árabe iba acompañado de un conocimiento de la lengua romance, valenciano en un principio y castellano más tarde.

Por otro lado, también es cuestión ardua el dilucidar en qué proporción ese conocimiento del árabe estaba limitado a su uso oral o, si bien, entre la población mudéjar valenciana estaba más o menos extendida la escritura en caracteres árabes. Si bien es conocido que ciertos individuos pertenecientes a una élite económica o cultural (comerciantes, oficiales reales, alfaquíes, etc) conocían y usaban el árabe escrito hasta fechas que prácticamente lindan con los decretos de expulsión, los datos referentes a un espectro mucho más amplio de la población musulmana son más problemáticos en cuanto a su interpretación: por un lado, la circulación de amuletos y papeles con grafemas árabes inscritos puede no indicar mucho más que un uso mágico derivado del carácter taumatúrgico que el alifato había llegado a tener ${ }^{5}$; por otra parte, el mayor o menor conocimiento de la lengua árabe irá dependiendo cada

del segle XIII" (Burns, p. 17). Sin embargo, la opiniớn tradicional se verá extendida con los trabajos de Ubieto Arteta en los años 70 , y, así, S. Haliczer vuelve a afirmar, si bien con matizaciones: "In spite of the insistence of certain modern historians that the Moriscos preserved the use of some form of Arabic right down to the expulsion, the evidence suggests that large number of Moriscos could understand and speak Castilian or Valencian even if they continued to use Arabic among themselves" (Inquisition and Society in the Kingdom of Valencia, 1478-1834), Berkeley-Los Angeles, 1990, p. 249).

(3) Vid., por ejemplo, el caso que cita J. Boswell (The Royal Treasure: Muslim Communities under the Crown of Aragon in the Fourteenth Century, New Haven-London, 1977, p. 505; tb. en C. Barceló, Minorías islámicas en el País Valenciano, Valencia, 1984, p. 138) en el que un musulmán de Elche se queja en 1360 a la reina de que el baile pretende que traduzca "en cristianesch" un manual "de la cullita dels rendes e drets" a su costa. La reina ordenará al baile que, si necesita realmente traducirlo, lo haga a expensas de la corte y no del musulmán.

(4) Barceló, Minorías..., p. 138, 139; D. Romano, "Judíos escribanos y trujamanes en la Corona de Aragón", Sefarad, 38 (1978), pp. 71-105.

(5) Vid. P. Boronat, Los moriscos..., vol. I, p. 492. 
vez más, aparte del lugar de residencia, de que en los años de su educación la presión evangelizadora cristiana haya sido más acusada ${ }^{6}$.

Así, pues, puede establecerse con seguridad un conocimiento extendido del árabe hablado en su vertiente dialectal en la Valencia del siglo XV, junto a un conocimiento del árabe escrito mucho más restringido en cuanto a su extensión. Sin embargo, existe un fenómeno entre los mudéjares valencianos del siglo $\mathrm{XV}$ que obliga a poner matices, siquiera suposiciones, a esta afirmación.

Sabido es que entre los siglos XIII y XV son numerosos los mudéjares valencianos que marchan al Reino de Granada por asuntos diversos. Con alguna fluctuación este tráfico, que con bastante frecuencia resulta de una y definitiva dirección ${ }^{7}$, se mantendrá en número hasta que lleguen las primeras restricciones a la salida del Reino de Valencia. Durante el siglo XV no existe apenas inconveniente por parte de las autoridades cristianas en extender guiajes y salvoconductos para que los mudéjares marchen a Granada por asuntos como negociar, recuperar deudas, ver a los familiares o a estudiar.

Detengámonos en este último caso: ¿Qué era lo que estos mudéjares valencianos iban a estudiar al Reino de Granada? Fundamentalmente dos cosas: la primera, los conocimientos necesarios para poder ejercer el cargo de alfaquí de la aljama: estudios coránicos, la Sunna, todos los requisitos, en fin, para hacerse peritos en la ley islámica. Aún cuando esta iniciativa pueda sorprender un tanto al existir autoridades religiosas islámicas en el Reino de Valencia durante el siglo XV, puede comprenderse en el sentido de que en el todavía no conquistado reino de Granada el estudio de estas ciencias puede resultar mucho más continuado y sólido, con autoridades de más prestigio que en Valencia, donde los alfaquíes van quedando cada vez más aislados y más dedicados a enseñar los rudimentos de la fe islámica entre la masa de mudéjares desperdigados por la geografía valenciana. La elección de Granada se vuelve, si no estrictamente necesaria, sí recomendable.

La segunda de las cosas que los mudéjares valencianos declaran ir a aprender a Granada es, quizá, más simple, pero igualmente vital para su propia idiosincrasia: la lengua árabe. Ahora bien, ¿no estaba extendido el árabe en Valencia durante el siglo XV? Por esta época incluso se están realizando fatigosas traducciones de

(6) Vid. M. C. Barceló, Minorías..., pp. 141-143.

(7) Vid. J. Hinojosa, "Las relaciones entre los reinos de Valencia y Granada durante la primera mitad del siglo XV", en: Estudios de Historia de Valencia, Valencia, 1978, pp. 91-160. 
libros científicos y religiosos en Valencia ${ }^{8}$, ¿por qué marchar entonces al Reino de Granada?

Tomemos a título de ejemplo tres casos que J. Hinojosa recoge de la documentación de la Bailía referentes a febrero-marzo de $1476^{\circ}$ :

1476, febrero, 23, Valencia.

Guiaje a favor de Eça, hijo de Mahomat Hiole, de Bụnol, que va a Granada a aprender a leer y escribir árabe.

1476, marzo, 3, Valencia.

Guiaje a favor de Alí Benaley, de la Vall de Garig, que va a Almería a aprender árabe.

1476, marzo, 4, Valencia.

Salvoconducto a favor de Yahie Benaley, de la Vall de Garig, que va a Almería a aprender árabe y a acompañar a Alí Benaley.

De la lectura de estos tres casos pueden extrapolarse tanto unas dudas como unas impresiones. En primer lugar, lo más evidente, ¿poseían algún tipo de competencia en la lengua árabe? En el caso de Eça Hiole de Buñol parece que al menos sí poseía la capacidad de hablarlo, puesto que se especifica que va a aprender a leer y escribir la lengua árabe; en los otros dos casos de Alí y Yahie Benaley de la Vall de Garig, simplemente se afirma que van a aprender árabe a Almería, como si ya ni siquiera tuvieran la competencia oral en dicha lengua.

En cualquier caso, con el primer ejemplo al menos, estamos ante un caso prototípico de la enorme diglosia que afectaba a la población islámica valenciana: capaz de hablar en el árabe de sus mayores, el árabe dialectal valenciano, está incapacitada, sin embargo, para poder leer los caracteres de un texto como el Corán y, posiblemente, para entender parte de su recitación. En este sentido, la marcha a Granada responde a un intento, digamos, de "escolarización", de poder aprehender el utillaje imprescindible para avanzar en el conocimiento de su religión y de su cultura que hasta ahora sólo conocían a través de un lenguaje familiar interno. Mucho más, por supuesto, en el segundo de los casos si aceptamos la premisa de

(8) Vid. L. García Ballester, Historia social de la medicina en la España de los siglos XIII al XVI, Madrid, 1976, p. 72. Conviene tomar en cuenta también un caso como el del antiguo alfaquí de Xàtiva convertido al cristianismo en 1487, Juan Andrés, que, según propio testimonio, tradujo del árabe al aragonés el Corán y la Sunna (Vid. J. El Kolli, La polémique islamo-chrétienne en Espagne (1492-1640) à travers les refutations de l'Tslam de Juan Andrés et Lope Obregón, Montpellier, 1983 [Thèse pour le Doctorat], 113-114).

(9) J. Hinojosa, Documentación medieval alicantina en el Archivo del Reino de Valencia, Alicante, 1986, p. 122 . 
que la competencia lingüística de esos mudéjares de la Vall de Garig se limitaba simplemente al romance.

Sin embargo, en todos estos casos sigue presentándose una pregunta fundamental: ¿Por qué ir a Granada? ¿Por qué marchar cientos de kilómetros al sur atravesando varios reinos cuando consta la presencia de personas que usaban y enseñaban la lengua árabe por estas mismas fechas en el reino de Valencia?

Parece difícil una sola respuesta que de completa respuesta a este interrogante. Quizá haya que pensar en una respuesta parecida a la de los estudios de alfaquí: en Granada sus estudios pueden ser más completos y "fiables", dando así una carta de autoridad a sus futuros conocimientos; sin embargo, esta solución comporta el aprendizaje de otra variedad del árabe hispano, la granadina, y seguramente no del árabe clásico. Puede, por otra parte, que la respuesta gire parcialmente en torno a una voluntad de no retorno: puesto que la voluntad de esos mudéjares era establecerse en el Reino de Granada, y dadas las escasas restricciones de las autoridades cristianas para el desplazamiento, quizá el motivo del viaje era lo de menos.

En cualquier caso, lo que parece necesario es seguir atendiendo en este punto a los casos particulares para que, una vez analizados éstos cuantitativa y cualitativamente, puedan establecese las debidas consideraciones a las conclusiones generales. $\mathrm{El}$ que unos determinados mudéjares valencianos hubieran perdido su capacidad de comunicarse en árabe, aunque poco frecuente, no es, en sí, un hecho inexplicable. Lo que sigue planteando dudas es, sin embargo, que recorran cientos de kilometros para hallar algo que hubieran podido encontrar muy cerca de su propia casa. 